Research Paper

\title{
Effects of Tranexamic Acid Based on its Population Pharmacokinetics in Pediatric Patients Undergoing Distraction Osteogenesis for Craniosynostosis: Rotational Thromboelastometry (ROTEM ${ }^{\mathrm{TM}}$ ) Analysis
}

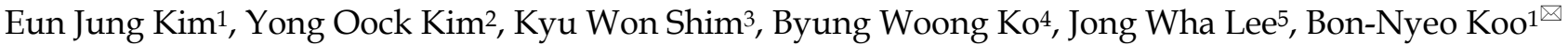 \\ 1. Department of Anesthesiology and Pain Medicine, Anesthesia and Pain Research Institute, Yonsei University College of Medicine, Seoul, Republic of Korea \\ 2. Department of Plastic and Reconstructive Surgery, Institute for Human Tissue Restoration, Yonsei University College of Medicine, Seoul, Republic of Korea \\ 3. Department of Pediatric Neurosurgery, Craniofacial Reforming and Reconstruction Clinic, Yonsei University College of Medicine, Seoul, Republic of Korea \\ 4. Department of Anesthesiology and Pain Medicine, Yonsei University College of Medicine, Seoul, Republic of Korea \\ 5. Department of Anesthesiology and Pain Medicine, Ewha Womans University School of Medicine, Seoul, Republic of Korea
}

$\square$ Corresponding authors: Jong Wha Lee, MD, Department of Anesthesiology and Pain Medicine, Ewha Womans University School of Medicine, 1071, Anyangcheon-ro, Yangcheon-gu, Seoul 07985, Korea. Phone: +82-2-2650-5285; Fax: +82-2-2655-2924; E-mail: jhanes@ewha.ac.kr and Bon-Nyeo Koo, MD, PhD, Department of Anaesthesiology and Pain Medicine, Anaesthesia and Pain Research Institute, Yonsei University College of Medicine, 50-1 Yonsei-ro, Seodaemun-gu, Seoul 03722, Republic of Korea. Phone: +82-2-2228-8513; Fax: +82-2-2227-7897; E-mail: KOOBN@yuhs.ac

(c) Ivyspring International Publisher. This is an open access article distributed under the terms of the Creative Commons Attribution (CC BY-NC) license (https://creativecommons.org/licenses/by-nc/4.0/). See http://ivyspring.com/terms for full terms and conditions.

Received: 2018.01.18; Accepted: 2018.04.12; Published: 2018.05.22

\begin{abstract}
Background: Distraction osteogenesis for craniosynostosis is associated with significant hemorrhage. Additionally, patients usually require several transfusions. Tranexamic acid (TXA) is effective for reducing blood loss and the need for transfusions during surgeries. However, the significance of TXA infusion has not been thoroughly described yet.

Methods: Forty-eight children undergoing distraction osteogenesis for craniosynostosis were administered intraoperative TXA infusion (loading dose of $10 \mathrm{mg} / \mathrm{kg}$ for $15 \mathrm{~min}$, followed by continuous infusion at $5 \mathrm{mg} / \mathrm{kg} / \mathrm{h}$ throughout surgery; $n=23$ ) or normal saline (control, $n=25$ ). Rotational thromboelastometry $\left(\right.$ ROTEM $\left.^{T M}\right)$ was conducted to monitor changes in coagulation perioperatively.

Results: Blood loss during surgery was significantly lower in the TXA-treated group than it was in the control group ( $81 \mathrm{vs.} 116 \mathrm{~mL} / \mathrm{kg}, P=0.003)$. Furthermore, significantly fewer transfusions of red blood cells and fresh frozen plasma were required in the TXA group. In the control group, clotting time during the postoperative period was longer than it was during the preoperative period. Similarly, clot strength was weaker during the postoperative period. D-dimer levels dramatically increased in the control group compared with the TXA group after surgery. The duration of mechanical ventilation and the number of postoperative respiratory-related complications were significantly greater in the control group than they were in the TXA group.

Conclusions: TXA infusion based on population pharmacokinetic analysis is effective in reducing blood loss and the need for transfusions during the surgical treatment of craniosynostosis. It can also prevent the increase in D-dimer levels without affecting systemic hemostasis.
\end{abstract}

Key words: tranexamic acid; rotational thromboelastometry; craniosynostosis; transfusion

\section{Introduction}

Premature fusion of cranial sutures with resultant cranial distortion is termed craniosynostosis. The treatments for craniosynostosis are diverse, ranging from cranial molding helmet to distraction osteogenesis [1], which must be performed within one year of birth to allow the affected bones to be resolved 
and regenerated without further defects [2]. Distraction osteogenesis is usually accompanied by relatively high blood loss and the subsequent need for blood transfusion in children aged $<1$ year.

Tranexamic acid (TXA) is a synthetic lysine analog that inhibits the proteolytic action of plasmin on fibrin clots and platelet receptors, thereby inhibiting fibrinolysis $[3,4]$. It is efficient in reducing blood loss during surgery [5-8]. Currently, there are no concrete protocols for its use; however, there are reports on its population pharmacokinetics in different surgeries $[5,9,10]$. The hemostatic efficacy of TXA in children undergoing distraction osteogenesis has not been fully described.

Rotational thromboelastometry (ROTEM ${ }^{\mathrm{TM}}$ ) is used in the perioperative management of hemorrhage [11] and transfusion [12, 13]. It is effective in reducing the need for the transfusion of any allogenic blood product. Additionally, it is substantially cost-effective [14].

The goals of this prospective, randomized, double-blind, placebo-controlled study were to evaluate the effects of TXA infusion based on its population pharmacokinetics by assessing blood loss and transfusion requirement in children undergoing distraction osteogenesis for craniosynostosis and to observe the impact of TXA on overall hemostasis by performing ROTEM ${ }^{\mathrm{TM}}$ analysis.

\section{Materials and Methods}

\section{Study participants}

The study protocol was approved by the Institutional Review Board of the Severance Hospital of the Yonsei University Health System (Seoul, South Korea; IRB No. 4-2014-0274; June 3, 2014) and registered at http://clinicaltrials.gov (NCT02180321). Written informed consent was obtained from the parent or legal guardian of each patient. Fifty children who were scheduled for distraction osteogenesis for craniosynostosis were recruited in this study. Exclusion criteria were as follows: platelet count $(\mathrm{PLT}),<50 \times 10^{3} / \mu \mathrm{L}$; prothrombin time $(\mathrm{PT})$ or activated partial thromboplastin time $(\mathrm{aPTT})>1.5$ times the reference value; history of convulsive seizure, epilepsy, or brain surgery; treatment with a non-steroidal anti-inflammatory agent within the previous 2 days; treatment with aspirin within 14 days prior to surgery; and known allergy to TXA. Patients were evenly assigned to two groups (TXA or control) using computer-generated randomized tables. The group allocations were noted in sequentially numbered, sealed, and opaque envelopes. A research assistant who was not a study investigator opened the envelopes and prepared the infusions according to the group allocations. Besides the designated research assistant who prepared the study drugs, all study participants and care providers were blinded to the randomization. None of the patients received any antifibrinolytic agent prior to surgery.

\section{Management of anesthesia}

The following standardized general anesthesia protocol was used: induction with $2 \mathrm{mg} / \mathrm{kg}$ propofol and $1 \mu \mathrm{g} / \mathrm{kg}$ fentanyl, neuromuscular blockade with $0.6 \mathrm{mg} / \mathrm{kg}$ rocuronium bromide, maintenance with desflurane or sevoflurane in an oxygen-air mixture (fraction of inspired oxygen, 0.5), and administration of intermittent bolus doses of fentanyl and rocuronium. A central venous catheter was placed in the femoral or internal jugular vein, whereas an arterial catheter was placed in the radial artery. Urine output was monitored using a urinary catheter. Rectal temperature was measured and maintained at normothermic levels with a forced-air blanket throughout the surgery. TXA was administered as an intravenous loading dose of $10 \mathrm{mg} / \mathrm{kg}$ over $15 \mathrm{~min}$, followed by continuous intravenous infusion at 5 $\mathrm{mg} / \mathrm{kg} / \mathrm{h}$ from the beginning of the surgery until skin closure [5]. Normal saline was similarly administered throughout the surgery to the control group.

\section{Transfusion strategies}

The need for perioperative transfusion was determined according to the transfusion guidelines and agreement by both the surgical and anesthesia care teams [11, 15] as follows: packed red blood cells (RBC) transfusion in response to early clinical signs of circulatory shock, significant decrease in blood pressure with a hematocrit (Hct) $<30 \%$, acute intraoperative blood loss $\geq 15 \%$ of estimated blood volume (EBV), Hct $<24 \%$ with signs of anemia, and clinical coagulopathy requiring hemostatic blood product transfusion (PLT $<50 \times 10^{3} / \mu \mathrm{L}$ or international normalized ratio $>2$ times the reference value) with either excessive microvascular bleeding or active bleeding $[11,16]$. Blood products were filtered and irradiated prior to transfusion.

Hemoglobin/Hct, PLT, PT, and aPTT were determined before the study drugs were administered, serially at every 60 min during surgery, at the end of the surgery, and on postoperative days 1 and 2. The levels of fibrinogen and D-dimer were measured before the study drugs were administered and at the end of the surgery.

\section{Distraction osteogenesis}

All the patients underwent distraction osteogenesis to correct cranial deformities. Osteotomy was performed according to the relevant design for 
the specific diagnosis of craniosynostosis. After successful osteotomy and bone flap elevation, distraction devices (Jeil Medical Corp., Seoul, Republic of Korea) were fixed. The number of distraction devices required was determined based on the type of osteotomy $[1,17]$. Patients were monitored in the neurosurgical intensive care unit for 1-2 days after surgery.

\section{Outcome measures}

Due to the inaccuracy in estimating blood loss during surgery, blood loss was calculated by the anesthesiologist using a previously adopted formula for this patient population $[6,18,19]$ :

Estimated red cell volume $(E R C V)_{\text {lost }}=\mathrm{ERCV}_{\text {preoperative }}$ $+\mathrm{ERCV}_{\text {transfused }}-\mathrm{ERCV}_{\text {postoperative }}$

where $\mathrm{ERCV}$ is $\mathrm{EBV} \times \mathrm{Hct} / 100$.

EBV is $80 \mathrm{~mL} / \mathrm{kg}$ for infants younger than 12 months and $75 \mathrm{~mL} / \mathrm{kg}$ for children older than 12 months. ERCV $V_{\text {transfused }}$ was calculated as follows:

$\mathrm{ERCV}_{\text {transfused }}=$ transfused volume of packed $\mathrm{RBC}$

$$
(\mathrm{mL}) \times \text { Hct of packed RBC/100 }
$$

Hct of packed RBC was estimated to be approximately $60 \%$ by the local blood bank. Therefore, $\mathrm{EBV}_{\text {lost }}$ was calculated as:

$$
\begin{gathered}
\mathrm{EBV}_{\text {lost }}(\mathrm{mL} / \mathrm{kg})=\mathrm{ERCV}_{\text {lost }}(\mathrm{mL}) /[\text { Weight }(\mathrm{kg}) \times \\
\text { Hct } \left._{\text {preoperative }} / 100\right]
\end{gathered}
$$

Routine fluid management during surgery consisted of continuous administration of balanced crystalloid with additional SD 1:4 solution $(0.2 \% \mathrm{NaCl}$ with dextrose). The amount of fluid administered was determined based on preoperative fasting time, intraoperative deficits, and basal fluid maintenance. Colloid [hydroxyethyl starch $(6 \%, 130 / 0.4)$ in a balanced electrolyte solution, Volulyte; Fresenius Kabi, Schelle, Belgium] up to $20 \mathrm{~mL} / \mathrm{kg} /$ day was administered in case of acute and massive perioperative blood loss prior to the initiation of blood product preparation and transfusion. Controlled hypotension was not performed during surgery. The scalp was infiltrated with local anesthetics containing epinephrine during the surgical procedure.

ROTEM $^{\mathrm{TM}}$ analyses were performed three times during the study period: prior to administration of the study drugs (T0), immediately after surgery (T1), and $24 \mathrm{~h}$ after surgery (T2). Blood samples for ROTEMTM analyses were drawn from an indwelling arterial catheter. Clot formation, propagation, and strength were evaluated extrinsically (EXTEM, extrinsically activated test with tissue factor) and intrinsically (INTEM, intrinsically activated test using ellagic acid). In addition, an extrinsically activated test was performed using the platelet-blocking substance cytochalasin D (FIBTEM, fibrin-based extrinsically activated test with tissue factor and the platelet inhibitor cytochalasin D) for the separate evaluation of functional fibrin polymerization without platelet activity. All ROTEM ${ }^{\mathrm{TM}}$ analyses were performed according to standard protocols with a minimum running time of $60 \mathrm{~min}$ by a designated experienced anesthesiologist (JWL).

During regular postoperative follow-ups, the patients were examined for any clinical evidence of TXA-related adverse events, such as clinically evident thromboembolic or neurologic events, until 3 months after the surgery.

\section{Statistical analysis}

The primary objective of this study was to compare blood loss and transfusion requirement between the TXA and control groups. The secondary objective was to evaluate the hemostatic effect of TXA by performing ROTEM ${ }^{\mathrm{TM}}$ analyses. For a statistical power of 0.80 , a group size of at least 23 was obtained from calculations to detect a large effect size of 0.85 by using a two-tailed test $(\alpha=0.05)$ [6]. Considering potential dropout rates, investigators decided to enroll 25 patients per group. Data are presented as mean \pm standard deviation or median (interquartile range) for continuous variables based on the Kolmogorov-Smirnov normality test or number of patients (percentage) for categorical variables. Student's $t$-test or Mann-Whitney $U$-test was used depending on the underlying distribution to detect differences in results between the TXA and control groups. Repeatedly measured variables, such as hemoglobin/Hct, PLT, PT, and aPTT were analyzed using linear mixed models with Bonferroni correction. Statistical analyses were performed using SPSS for Windows (version 23.0; SPSS Inc., Chicago, IL, USA). $P<0.05$ was considered statistically significant.

\section{Results}

Fifty patients, aged 4 months to 5 years, were enrolled in the study from July 2014 to March 2016. Two patients in the TXA group were excluded from the analysis because of an error in the ROTEM ${ }^{\mathrm{TM}}$ analysis. Patient demographics and surgery-related data were comparable between the two groups (Table $1)$.

Intraoperative blood loss was significantly lower in the TXA group than it was in the control group (81 vs. $116 \mathrm{~mL} / \mathrm{kg} ; P=0.003)$. Although the same transfusion guidelines were followed for both groups, the amount of blood products administered intraoperatively was significantly lower in the TXA group than it was in the control group [packed RBC, 
49 vs. $65 \mathrm{~mL} / \mathrm{kg}, P=0.010$; fresh frozen plasma (FFP), 19 vs. $28 \mathrm{~mL} / \mathrm{kg}, P=0.038$ ]. Moreover, no patient in the TXA group was administered a blood product postoperatively, except for two patients who were administered FFP on postoperative day 1 (Table 2). The amount of crystalloid administered during surgery was comparable between the two groups; however, a significantly smaller volume of colloids was administered intraoperatively in the TXA group than in the control group (17 vs. $20 \mathrm{~mL} / \mathrm{kg}, P=0.026$ ). Although the number of patients treated with diuretics and the amount of diuretics administered perioperatively were comparable between the two groups (data not shown), urine output was lower in the TXA group than it was the control group on postoperative day $1(59.4$ vs. $80.0 \mathrm{~mL} / \mathrm{kg}, P=0.010$; Table 2).

Table 1. Patient Characteristics and Surgery-related Data.

\begin{tabular}{|c|c|c|c|}
\hline & TXA $(n=23)$ & $\begin{array}{l}\text { Control } \\
(\mathrm{n}=25)\end{array}$ & $P$-value \\
\hline Age (months) & $12(7-22)$ & $14(8-30)$ & 0.380 \\
\hline Male, n (\%) & $14(61)$ & $10(40)$ & 0.153 \\
\hline Height (cm) & $76.7 \pm 8.1$ & $80.0 \pm 11.4$ & 0.256 \\
\hline Weight (kg) & $10.1 \pm 2.3$ & $10.7 \pm 2.6$ & 0.430 \\
\hline $\begin{array}{l}\text { Preoperative Medical Problem, } n \\
(\%)^{*}\end{array}$ & $11(48)$ & $13(52)$ & 0.775 \\
\hline Concomitant Features, n (\%) & $6(26)$ & $8(32)$ & 0.656 \\
\hline \multicolumn{4}{|l|}{ Diagnosis, n (\%) } \\
\hline Sagittal & $8(35)$ & $7(28)$ & 0.616 \\
\hline Metopic & $2(9)$ & $0(0)$ & 0.136 \\
\hline Unilateral coronal & $5(22)$ & $2(8)$ & 0.182 \\
\hline Bilateral coronal & $2(9)$ & $3(12)$ & 0.711 \\
\hline Lambdoid & $2(9)$ & $3(12)$ & 0.711 \\
\hline Multiple & $4(17)$ & $10(40)$ & 0.088 \\
\hline Duration of Surgery (min) & $264.0 \pm 75.1$ & $262.6 \pm 48.4$ & 0.939 \\
\hline Duration of Anesthesia (min) & $326.1 \pm 58.4$ & $352.4 \pm 45.3$ & 0.086 \\
\hline \multicolumn{4}{|c|}{$\begin{array}{l}\text { Values are mean } \pm \text { standard deviation, median (interquartile range), or number of } \\
\text { patients (percentage). }\end{array}$} \\
\hline \multicolumn{4}{|c|}{$\begin{array}{l}\text { TXA: tranexamic acid; ASA: American Society of Anesthesiology physical status } \\
\text { classification. }\end{array}$} \\
\hline \multicolumn{4}{|c|}{$\begin{array}{l}\text { * Preoperative medical problems: Abnormal electrocardiogram, abnormal chest } \\
\text { x-ray, mildly increased serum liver enzyme levels (aspartate aminotransferase and } \\
\text { alanine aminotransferase) }\end{array}$} \\
\hline
\end{tabular}

Preoperative baseline Hct, PLT, fibrinogen level, PT, aPTT, and D-dimer level did not differ significantly between the two groups. However, Hct was significantly higher in the TXA group than it was in the control group at the end of surgery and on postoperative day 2 [32 vs. $29 \%(P=0.048)$ and 35 vs. $30 \%(P=0.034)$, respectively]. Similarly, PLT was significantly higher in the TXA group on postoperative day $2\left(267\right.$ vs. $194 \times 10^{3} / \mu \mathrm{L}, P=0.010$; Fig. $1 \mathrm{~A}$ and $1 \mathrm{~B}$, respectively). Postoperative aPTT at the end of surgery was significantly longer in the control group than it was in the TXA group (36 vs. 41 $\mathrm{s}, P=0.028$; Fig. 1D). Furthermore, D-dimer level dramatically increased after surgery in the control group; however, the increase in D-dimer level was suppressed in the TXA group (Fig. 1F). Compared with preoperative baseline values, PT was significantly prolonged and fibrinogen level was significantly reduced after surgery in both groups (Fig. 1C and 1E); however, these parameters were comparable between the two groups.

Table 2. Perioperative Fluid Management Between Groups.

\begin{tabular}{|c|c|c|c|c|}
\hline & & $\begin{array}{l}\text { TXA } \\
(n=23)\end{array}$ & $\begin{array}{l}\text { Control } \\
(n=25)\end{array}$ & $P$-value \\
\hline \multicolumn{5}{|c|}{ Intraoperative Input } \\
\hline \multirow[t]{12}{*}{ period } & Crystalloid (mL/kg) & $35.5(26.1-41.2)$ & $29.1(21.7-38.2)$ & 0.151 \\
\hline & Colloid (mL/kg) & $16.7(14.1-20.0)$ & $20.0(16.7-20.0)$ & 0.038 \\
\hline & Packed RBC (mL/kg) & $48.8 \pm 16.8$ & $65.2 \pm 24.2$ & 0.010 \\
\hline & $\mathrm{FFP}(\mathrm{mL} / \mathrm{kg})$ & $19.4 \pm 13.0$ & $28.1 \pm 15.1$ & 0.038 \\
\hline & $\begin{array}{l}\text { platelet concentrate } \\
(\mathrm{mL} / \mathrm{kg})\end{array}$ & $5.9(0-12.9)$ & $10(2.1-16.9)$ & 0.217 \\
\hline & \multicolumn{4}{|c|}{ Number of patients receiving transfusion } \\
\hline & Packed RBC & $23(100)$ & $25(100)$ & $>0.999$ \\
\hline & FFP & $23(100)$ & $25(100)$ & $>0.999$ \\
\hline & platelet concentrate & $14(61)$ & $20(80)$ & 0.149 \\
\hline & Output & & & \\
\hline & Blood loss (mL/kg) & $80.6 \pm 33.3$ & $115.6 \pm 43.6$ & 0.003 \\
\hline & Urine Output (mL/kg) & $29.8(18.2-33.8)$ & $29.8(18.7-43.3)$ & 0.828 \\
\hline \multirow{13}{*}{$\begin{array}{l}\text { Postoperative } \\
\text { day } 1\end{array}$} & Input & & & \\
\hline & Crystalloid (mL/kg) & $78.5 \pm 23.1$ & $83.1 \pm 29.8$ & 0.557 \\
\hline & Colloid (mL/kg) & - & - & \\
\hline & Packed RBC (mL/kg) & - & $0(0-7.4)$ & 0.003 \\
\hline & $\mathrm{FFP}(\mathrm{mL} / \mathrm{kg})$ & $0(0-0)$ & $0(0-0)$ & $>0.999$ \\
\hline & $\begin{array}{l}\text { platelet concentrate } \\
(\mathrm{mL} / \mathrm{kg})\end{array}$ & - & $0(0-0)$ & 0.090 \\
\hline & \multicolumn{4}{|c|}{ Number of patients receiving transfusion } \\
\hline & Packed RBC & 0 & $8(32)$ & 0.003 \\
\hline & FFP & $2(9)$ & $2(8)$ & $>.999$ \\
\hline & PLT & 0 & $3(12)$ & 0.090 \\
\hline & Output & & & \\
\hline & Blood loss (mL/kg) & $5.3(3.4-8.0)$ & $4.1(2.3-7.2)$ & 0.252 \\
\hline & Urine Output (mL/kg) & $59.4(48.4-67.0)$ & $80.0(54.0-95.6)$ & 0.010 \\
\hline \multirow{13}{*}{$\begin{array}{l}\text { Postoperative } \\
\text { day } 2\end{array}$} & Input & & & \\
\hline & Crystalloid (mL/kg) & $57.4(44.4-64.5)$ & $54.1(48.0-74.3)$ & 0.570 \\
\hline & Colloid (mL/kg) & - & - & \\
\hline & Packed RBC (mL/kg) & - & $0(0-0)$ & 0.025 \\
\hline & $\mathrm{FFP}(\mathrm{mL} / \mathrm{kg})$ & - & $0(0-0)$ & 0.337 \\
\hline & $\begin{array}{l}\text { platelet concentrate } \\
(\mathrm{mL} / \mathrm{kg})\end{array}$ & - & - & $>0.999$ \\
\hline & \multicolumn{4}{|c|}{ Number of patients receiving transfusion } \\
\hline & Packed RBC & 0 & $5(20)$ & 0.025 \\
\hline & FFP & 0 & $1(4)$ & 0.337 \\
\hline & platelet concentrate & 0 & 0 & $>0.999$ \\
\hline & Output & & & \\
\hline & Blood loss (mL/kg) & $1.3(0.8-2.1)$ & $1.3(0.9-2.1)$ & 0.926 \\
\hline & Urine Output (mL/kg) & $64.6(56.5-83.0)$ & $66.9(46.3-94.6)$ & 0.703 \\
\hline
\end{tabular}

Values are mean \pm standard deviation, median (interquartile range), or number of patients (percentage). TXA: tranexamic acid; OR: odds ratio; packed RBC: packed red blood cells; FFP: fresh frozen plasma.

ROTEM ${ }^{\mathrm{TM}}$ analyses showed no significant differences in EXTEM, INTEM, or FIBTEM between the two groups (Fig. 2); however, differences in some ROTEM $^{\mathrm{TM}}$ data were significant when preoperative baseline values were compared with the respective values at the end of surgery. For EXTEM, initiation and propagation of clot formation were delayed at the end of surgery in the control group. In addition, clot strength, which is based on clot amplitude at $10 \mathrm{~min}$ 
after clotting time (A10) and maximum clot firmness (MCF), reduced in both groups (Fig. 2A-D). For INTEM, prolonged clot propagation, decreased clot strength, increased clot formation time (CFT), and decreased A10 and MCF were observed at the end of surgery in both groups (Fig. 2E-H). Furthermore, lysis index at $30 \mathrm{~min}$ (percentage of clot firmness remaining after $30 \mathrm{~min}$ in relation to $\mathrm{MCF}$ ), lysis onset time (defined as the time needed for clot firmness to decrease by $15 \%$ of MCF), and maximum clot lysis were determined to assess the degree of fibrinolysis. No intergroup differences were noted in the lysis parameters. Changes in INTEM and EXTEM parameters from the preoperative baseline values were not observed on postoperative day 1 . Although fibrinogen levels significantly reduced in both groups, clot strength, based on the results of the FIBTEM analysis, significantly reduced only in the control group after surgery (Fig. 2I and 2J).

Mechanical ventilation time, which indicates the total duration of mechanical ventilation applied during the intraoperative and postoperative periods, was significantly shorter in the TXA group than it was in the control group ( 327 vs. $378 \mathrm{~min}, P=0.024$; Table $3)$. The number of patients with postoperative complications, such as pulmonary edema, pneumonia, and transfusion-related acute lung injury, was significantly higher in the control group than it was in the TXA group ( 0 vs. 4 [16\%], $P=0.047$ ). The total lengths of postoperative stay in the neurovascular care unit and the hospital were comparable between the two groups (Table 3). There was no incidence of convulsive seizure or a thromboembolic event in any patient during the study.
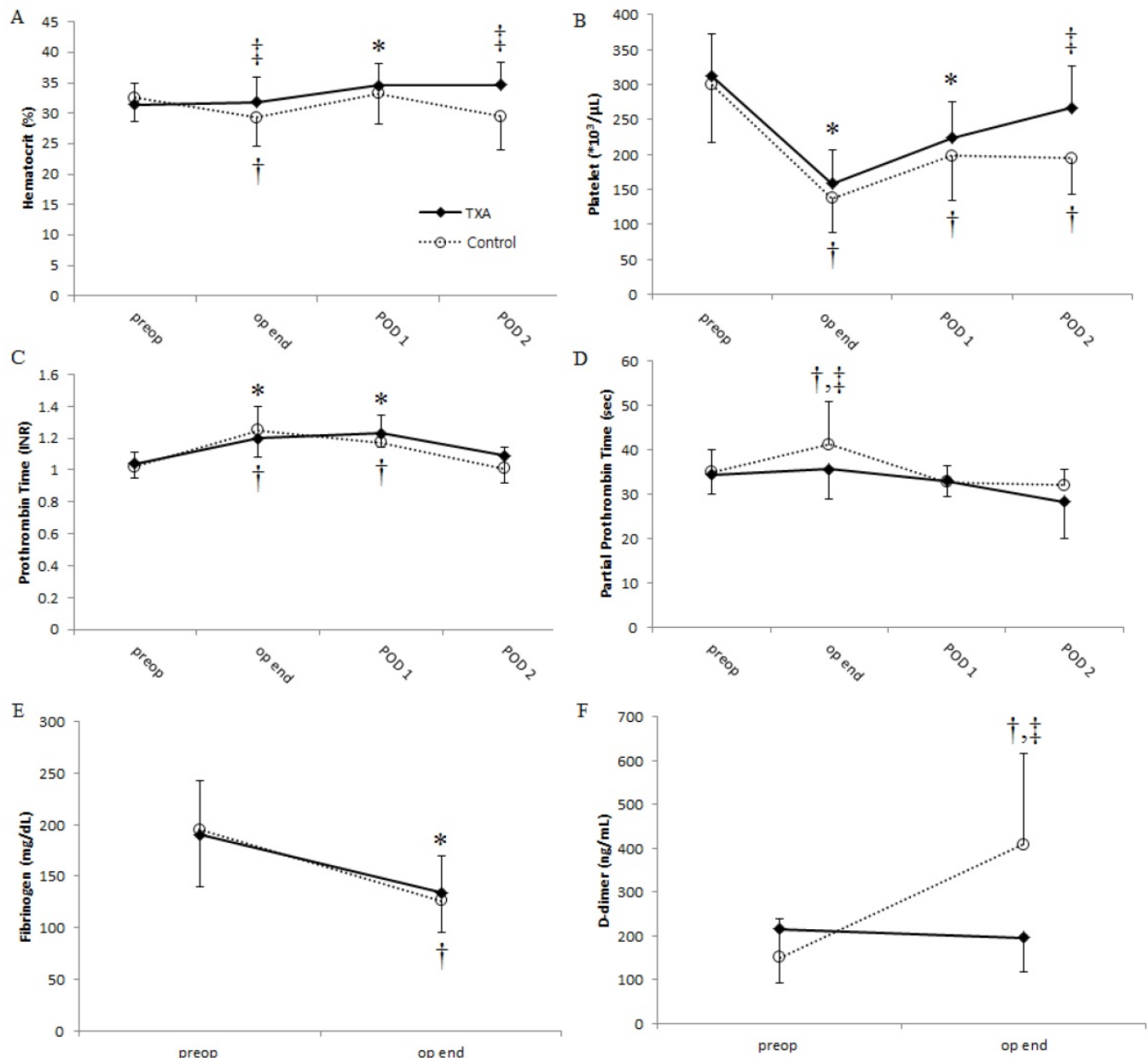

Figure 1. Changes in (A) hematocrit, (B) platelet count, (C) prothrombin time, (D) activated partial thromboplastin time, (E) fibrinogen level, and (F) D-dimer level over time in patients undergoing distraction osteogenesis for craniosynostosis between the TXA (solid lines) and control (dotted lines) groups. Values represent the mean, and error bars represent the standard deviation. $* P<0.05$ vs. baseline in the TXA group; $\uparrow P<0.05$ vs. baseline in the control group; $\ddagger P<0.05$ between the two groups. TXA: tranexamic acid; POD: postoperative day; preop: preoperative period; op end: at the end of surgery. 

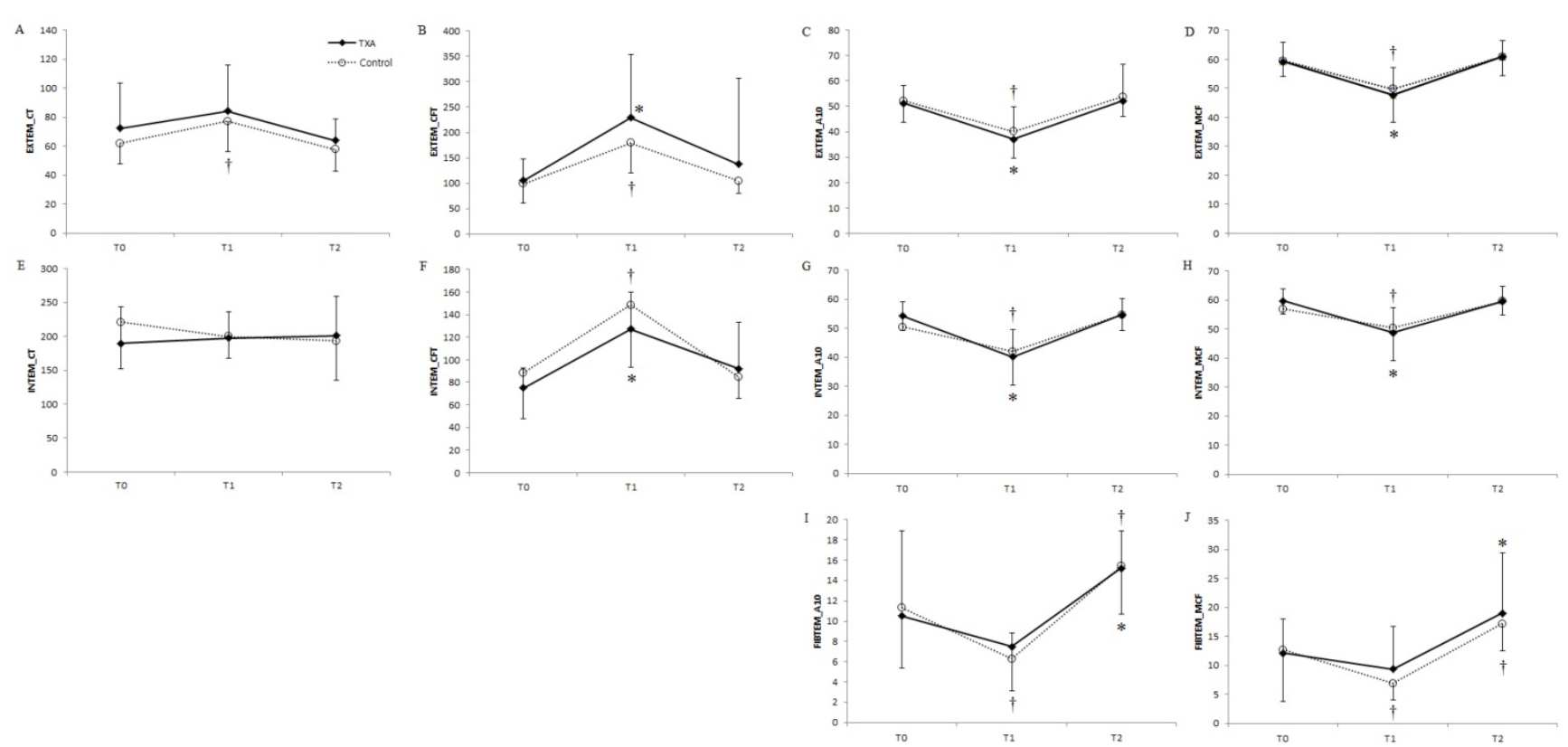

Figure 2. Changes in (A, E) CT of INTEM and EXTEM; (B, F) CFT of INTEM and EXTEM; (C, G, I) A10 of INTEM, EXTEM, and FIBTEM; (D, H, J) MCF of INTEM, EXTEM, and FIBTEM over time in patients undergoing distraction osteogenesis for craniosynostosis between the TXA (solid lines) and control (dotted lines) groups. Values represent the mean, and error bars represent standard deviation. $* P<0.05$ vs. baseline in the TXA group; $\nmid P<0.05$ vs. baseline in the control group. TXA: tranexamic acid; POD: postoperative day; preop: preoperative period; op end: at the end of surgery; CT: clotting time; EXTEM: extrinsically activated test; INTEM: intrinsically activated test; FIBTEM: fibrin-based extrinsically activated test; A10: clot amplitude at 10 min after clotting time; MCF: maximum clot firmness; CFT: clot formation time; APTEM: extrinsically activated test containing aprotinin.

Table 3. Postoperative Outcomes.

\begin{tabular}{|c|c|c|c|c|}
\hline & $\begin{array}{l}\text { TXA } \\
(n=23)\end{array}$ & $\begin{array}{l}\text { Control } \\
(\mathrm{n}=25)\end{array}$ & $\begin{array}{l}\text { Estimated } \\
\text { Treatment Effect }\end{array}$ & $\begin{array}{l}P- \\
\text { value }\end{array}$ \\
\hline NCU stay $(h)$ & $20(19-21.5)$ & $22(19-24.5)$ & $-1.0[-3.0$ to 0.5$]$ & 0.141 \\
\hline $\begin{array}{l}\text { Mechanical } \\
\text { ventilation time }(\mathrm{min})^{*}\end{array}$ & $326.5 \pm 65.8$ & $377.7 \pm 84.5$ & $51.2[-95.4$ to -6.9$]$ & 0.024 \\
\hline Complications, $\mathrm{n}(\%)^{* *}$ & $0(0)$ & $4(16)$ & $0.48[0.35$ & 0.047 \\
\hline Hospital stay (days) & $10.1 \pm 3.6$ & $10.9 \pm 5.1$ & $0.8[-3.4$ to 1.8$]$ & 0.542 \\
\hline \multicolumn{5}{|c|}{$\begin{array}{l}\text { Values are mean } \pm \text { standard deviation, median (interquartile range), or number of } \\
\text { patients (percentage). Estimated treatment effect is presented as mean difference } \\
{[95 \% \text { confidence interval] or relative risk [ } 95 \% \text { confidence interval]. }}\end{array}$} \\
\hline \multicolumn{5}{|c|}{ TXA: tranexamic acid; NCU: neurovascular care unit. } \\
\hline \multicolumn{5}{|c|}{$\begin{array}{l}\text { * Total duration of mechanical ventilation applied during intraoperative and } \\
\text { postoperative periods. }\end{array}$} \\
\hline \multicolumn{5}{|c|}{$\begin{array}{l}\text { ** Any event of pulmonary edema, pneumonia, or transfusion-related acute lung } \\
\text { injury. }\end{array}$} \\
\hline
\end{tabular}

\section{Discussion}

TXA administration based on dosing schemes derived from population pharmacokinetic analyses was shown to reduce blood loss and transfusion requirement. Although ROTEM $^{\mathrm{TM}}$ analysis failed to show TXA-induced changes in systemic hemostasis, it indicated significant changes in D-dimer levels. Furthermore, changes in FIBTEM indicated the preserved quality of fibrin-based clot at the end of surgery with subsequent hemostatic functional benefit following TXA administration [20-23].

The efficacy of TXA in reducing blood loss may differ depending on its plasma level [24, 25]. A previous pharmacokinetic study showed that systemic clearance of TXA was significantly reduced in patients weighing $\leq 10 \mathrm{~kg}$ or aged $\leq 12$ months. This suggests that caution should be taken when administering TXA to such patients, especially those scheduled for surgeries that result in massive bleeding and/or high transfusion requirement [5]. The results of recent investigations on the population pharmacokinetics of TXA have aided the development of a more precise protocol for TXA administration to pediatric patients $[5,9,10]$.

TXA-induced hemostasis involves inhibition of plasminogen-plasmin interactions on the surface of fibrin, thereby preventing fibrin degradation [3]. D-dimer is a protein product of cross-linked fibrin degradation, whose level in the blood elevates during hyperfibrinolysis and massive hemorrhage caused by fibrinolysis [26, 27]. D-dimer level had also shown clinical significance as a predictor of patient morbidity and transfusion requirement [29]. Although D-dimer could not be considered the gold standard measure of fibrinolysis, several studies had reported the antifibrinolytic effect of TXA related to blood loss and the changes in the levels of fibrinolysis markers, such as D-dimer, in various types of surgeries $[28,30]$. The suppressed increase in D-dimer level in the TXA group during the postoperative period observed in this study could be due to the antifibrinolytic action of TXA (Fig. 1F).

The antifibrinolytic activity of TXA resulted in reduced transfusion requirement until postoperative day 2 in this study. Although the mean half-life of 
TXA is $120 \mathrm{~min}$ [31], its hemostatic effect in patients, including children undergoing surgery for craniosynostosis treatment, can extend up to $24 \mathrm{~h}$ after it is discontinued [3,6,32]. This is considered as a residual effect at the surgical site, rather than a systemic effect $[6,33,34]$. However, despite the long-term effect of TXA in reducing the amount of transfusion required, no statistically significant difference was found between the two groups regarding the amount of blood lost during the postoperative period. Such lack of statistical significance may be attributed to the excessive hemorrhage in both groups, regardless of TXA administration. Although TXA effectively reduced intraoperative hemorrhage, the extent of blood loss (average, $>80 \mathrm{~mL} / \mathrm{kg}$ ) was equivalent to the total blood volume of an average 1-year-old child weighing approximately $10 \mathrm{~kg}$. The observed dramatic drop in PLT and fibrinogen level after surgery could have been caused by the massive hemorrhage.

ROTEM $^{\mathrm{TM}}$ analysis was performed before and after surgery to evaluate the changes in overall coagulation status. Prolonged CFT and a substantial drop in A10 and MCF in the EXTEM test at the end of surgery were attributed, in part, to decreased PLT and fibrinogen level from their respective baseline values in both groups. Significant blood loss was treated with packed RBC and FFP transfusions in the control group, which could have contributed to the reduced PLT and fibrinogen level. Consequently, no significant differences in the results of the ROTEM ${ }^{\mathrm{TM}}$ analysis were found between the two groups. In the control group, FIBTEM A10 and MCF, which are indicative of clot strength and fibrinogen activity, significantly reduced compared to their respective baseline values (Fig. 2I and 2J). This might have been due to a dilution effect caused by the significantly large amount of FFP transfused during surgery. Therefore, transfusing more concentrated fibrinogen supplements, such as cryoprecipitates, may be a better option when treating children with a smaller circulation volume. Moreover, although it had been restricted to $20 \mathrm{~mL} / \mathrm{kg} /$ day, the significantly large amount of colloid as a volume expander prior to transfusion in the case of acute and massive perioperative bleeding, may have affected the coagulation status and interfered with the ROTEM ${ }^{\mathrm{TM}}$ analysis. Colloids enhance fibrinolysis by diminishing $\mathrm{a}_{2}$-antiplasmin-plasmin interactions [35], thereby impeding fibrin formation and reducing fibrinogen-dependent clot strength [36, 37]. Although clinical data on the safe use of colloids in children are insufficient, some studies have shown that colloid infusions do not affect renal and coagulation systems in children $[38,39]$. One noticeable benefit of TXA during surgery is the decreased incidence of postoperative respiratory-related complications. Transfusion of packed RBC (> $60 \mathrm{~mL} / \mathrm{kg}$ ) and/or hemostatic products, such as FFP, platelet concentrates, and cryoprecipitates, was found to be an independent predictor of the occurrence of postoperative cardiorespiratory and hematological events [40]. The substantial number of transfusions received by patients in the control group may have prolonged mechanical ventilation time and resulted in a higher probability of respiratory-related complications (Table 3).

This study has several limitations. First, only packed RBC, FFP, and platelet concentrates were transfused due to the limited clinical availability of fibrinogen and cryoprecipitates. Second, the study design had limited the use of ROTEM ${ }^{\mathrm{TM}}$ analyses as the reference values for data interpretation, rather than the transfusion guidelines. Thirdly, in addition to EXTEM, INTEM, and FIBTEM, APTEM (extrinsically activated test containing aprotinin) could have been performed to enrich hemolytic profiles. This is because APTEM is useful when predicting the effects of antifibrinolytic agents on hyperfibrinolysis [41]. Moreover, randomized studies with a greater number of patients will be required to further investigate the discrepancy between the changes in the amount of blood loss and transfusion requirement and ROTEM ${ }^{\mathrm{TM}}$ analysis, especially with lysis parameters.

In conclusion, results of this study show that TXA administration based on the dosage regimen predicted from population pharmacokinetic analysis can be effective in reducing blood loss and transfusion requirement in pediatric patients undergoing distraction osteogenesis for craniosynostosis. Furthermore, the effects of antifibrinolytic agents on systemic hemostasis must be investigated in viscoelastic studies.

\section{Abbreviations}

ROTEM: rotational thromboelastometry; TXA: tranexamic acid; PLT: platelet count; PT: prothrombin time; aPTT: activated partial thromboplastin time; Hct: hematocrit; ERCV: estimated red cell volume; EBV: estimated blood volume; RBC: red blood cells; EXTEM: extrinsically activated test; INTEM: intrinsically activated test; FIBTEM: fibrin-based extrinsically activated test; FFP: fresh frozen plasma; A10: clot amplitude at $10 \mathrm{~min}$ after clotting time; MCF: maximum clot firmness; CFT: clot formation time; APTEM: extrinsically activated test containing aprotinin. 


\section{Acknowledgements}

This research was supported by Basic Science Research Program through the National Research Foundation of Korea (NRF) funded by the Ministry of Science, ICT \& Future Planning (NRF-2017R1C1B5017 506).

\section{Competing Interests}

The authors have declared that no competing interest exists.

\section{References}

1. Mundinger GS, Rehim SA, Johnson O, et al. Distraction Osteogenesis for Surgical Treatment of Craniosynostosis: A Systematic Review. Plast Reconstr Surg. 2016; 138:657-669.

2. Pattisapu JV, Gegg CA, Olavarria G, et al. Craniosynostosis: diagnosis and surgical management. Atlas Oral Maxillofacial Surg Clin N Am. 2010; 18:77-91.

3. Dunn CJ, Goa KL. Tranexamic acid: a review of its use in surgery and other indications. Drugs. 1999; 57:1005-1032.

4. Hoylaerts M, Lijnen HR, Collen D. Studies on the mechanism of the antifibrinolytic action of tranexamic acid. Biochim Biophys Acta. 1981; 673:75-85.

5. Goobie SM, Meier PM, Sethna NF, et al. Population pharmacokinetics of tranexamic acid in paediatric patients undergoing craniosynostosis surgery. Clin Pharmacokinet. 2013; 52:267-276.

6. Goobie SM, Meier PM, Pereira LM, et al. Efficacy of tranexamic acid in pediatric craniosynostosis surgery: a double-blind, placebo-controlled trial. Anesthesiology. 2011; 114:862-871.

7. Crantford JC, Wood BC, Claiborne JR, et al. Evaluating the safety and efficacy of tranexamic acid administration in pediatric cranial vault reconstruction. I Craniofac Surg. 2015; 26:104-107.

8. Dadure C, Sauter M, Bringuier S, et al. Intraoperative tranexamic acid reduces blood transfusion in children undergoing craniosynostosis surgery: a randomized double-blind study. Anesthesiology. 2011; 114:856-861.

9. Wesley MC, Pereira LM, Scharp LA, et al. Pharmacokinetics of tranexamic acid in neonates, infants, and children undergoing cardiac surgery with cardiopulmonary bypass. Anesthesiology. 2015; 122:746-758

10. Grassin Delyle S, Tremey B, Abe E, et al. Population pharmacokinetics of tranexamic acid in adults undergoing cardiac surgery with cardiopulmonary bypass. Br J Anaesth. 2013; 111:916-924

11. Practice guidelines for perioperative blood management: an updated report by the American Society of Anesthesiologists Task Force on Perioperative Blood Management. Anesthesiology. 2015; 122:241-275.

12. Schöchl H, Nienaber $U$, Maegele $M$, et al. Transfusion in trauma: thromboelastometry-guided coagulation factor concentrate-based therapy versus standard fresh frozen plasma-based therapy. Crit care. 2011; 15:R83.

13. Schöchl $H$, Cotton $B$, Inaba $K$, et al. FIBTEM provides early prediction of massive transfusion in trauma. Crit care. 2011; 15:R265.

14. Haas T, Spielmann N, Restin T, et al. Higher fibrinogen concentrations for reduction of transfusion requirements during major paediatric surgery: A prospective randomised controlled trial. Br I Anaesth. 2015; 115:234-243.

15. Roseff SD, Luban NL, Manno CS. Guidelines for assessing appropriateness of pediatric transfusion. Transfusion. 2002; 42:1398-1413.

16. Roback JD, Caldwell S, Carson J, et al. Evidence-based practice guidelines for plasma transfusion. Transfusion. 2010; 50:12271239.

17. Kim YO, Kim DS, Lee WJ, et al. Cranial growth after distraction osteogenesis of the craniosynostosis. I Craniofac Surg. 2008; 19:45-55.

18. Stricker PA, Shaw TL, Desouza DG, et al. Blood loss, replacement, and associated morbidity in infants and children undergoing craniofacial surgery. Paediatr Anaesth. 2010; 20:150-159.

19. Kearney RA, Rosales JK, Howes WJ. Craniosynostosis: an assessment of blood loss and transfusion practices. Can J Anesth. 1989; 36:473-477.

20. Haas T, Spielmann N, Mauch J, et al. Comparison of thromboelastometry (ROTEM $®$ ) with standard plasmatic coagulation testing in paediatric surgery. Br I Anaesth. 2012; 108:36-41.

21. Solomon C, Cadamuro J, Ziegler B, et al. A comparison of fibrinogen measurement methods with fibrin clot elasticity assessed by thromboelastometry, before and after administration of fibrinogen concentrate in cardiac surgery patients. Transfusion. 2011; 51:1695-1706.

22. Roullet S, Pillot J, Freyburger G, et al. Rotation thromboelastometry detects thrombocytopenia and hypofibrinogenaemia during orthotopic liver transplantation. Br J Anaesth. 2010; 104:422-428.

23. Rugeri L, Levrat A, David JS, et al. Diagnosis of early coagulation abnormalities in trauma patients by rotation thrombelastography. I Thromb Haemost. 2007; 5:289-295.

24. Murkin JM, Falter F, Granton J, et al. High-dose tranexamic Acid is associated with nonischemic clinical seizures in cardiac surgical patients. Anesth Analg. 2010; 110:350-353.
25. Ngaage DL, Bland JM. Lessons from aprotinin: is the routine use and inconsistent dosing of tranexamic acid prudent? Meta-analysis of randomised and large matched observational studies. Eur I Cardio-Thorac. 2010; 37:1375-1383.

26. Theusinger OM, Baulig W, Seifert B, et al. Relative concentrations of haemostatic factors and cytokines in solvent/detergent-treated and fresh-frozen plasma. Br I Anaesth. 2011; 106:505-511.

27. Olson J. D-dimer: An Overview of Hemostasis and Fibrinolysis, Assays, and Clinical Applications. Adv Clin Chem. 2015; 69:1-46.

28. Jansen AJ, Andreica S, Claeys M, et al. Use of tranexamic acid for an effective blood conservation strategy after total knee arthroplasty. Br I Anaesth. 1999; 83:596-601.

29. Hayakawa M, Maekawa K, Kushimoto S, et al. High d-dimer levels predict a poor outcome in patients with severe trauma, even with higher fibrinogen levels on arrival: a multicenter retrospective study. Shock. 2016; 45:308-314.

30. Faraoni D, Cacheux C, Van Aelbrouck C, et al. Effect of two doses of tranexamic acid on fibrinolysis evaluated by thromboelastography during cardiac surgery: a randomized, controlled study. Eur I Anaesthesiol 2014; 31:491-498.

31. Dowd NP, Karski JM, Cheng DC, et al. Pharmacokinetics of tranexamic acid during cardiopulmonary bypass. Anesthesiology. 2002; 97:390-399.

32. Durán de la Fuente P, García Fernández J, Pérez López C, Carceller F, Gilsanz Rodríguez F. [Usefulness of tranexamic acid in cranial remodeling surgery]. Rev Esp Anestesiol Reanim. 2003; 50:388-394.

33. Neilipovitz DT, Murto K, Hall L, Barrowman NJ, Splinter WM. A randomized trial of tranexamic acid to reduce blood transfusion for scoliosis surgery. Anesth Analg. 2001; 93:82-87.

34. Abrishami A, Chung F, Wong J. Topical application of antifibrinolytic drugs for on-pump cardiac surgery: a systematic review and meta-analysis. Can J Anesth. 2009; 56:202-212.

35. Nielsen VG. Hydroxyethyl starch enhances fibrinolysis in human plasma by diminishing alpha2-antiplasmin-plasmin interactions. Blood Coagul Fibrin. 2007; 18:647-656

36. Niemi T, Suojaranta Ylinen RT, Kukkonen SI, Kuitunen AH. Gelatin and hydroxyethyl starch, but not albumin, impair hemostasis after cardiac surgery. Anesth Analg. 2006; 102:998-1006.

37. Niemi T, Kuitunen AH. Artificial colloids impair haemostasis. An in vitro study using thromboelastometry coagulation analysis. Acta Anaesth Scand. 2005; 49:373-378

38. Standl T, Lochbuehler H, Galli C, et al. HES 130/0.4 (Voluven) or human albumin in children younger than 2 yr undergoing non-cardiac surgery. A prospective, randomized, open label, multicentre trial. Eur I Anaesth. 2008; 25:437-445.

39. Van der Linden P, De Villé A, Hofer A, Heschl M, Gombotz H. Six percent hydroxyethyl starch $130 / 0.4$ (Voluven ${ }^{\circledR}$ ) versus $5 \%$ human serum albumin for volume replacement therapy during elective open-heart surgery in pediatric patients. Anesthesiology. 2013; 119:1296-1309.

40. Goobie SM, Zurakowski D, Proctor MR, et al. Predictors of clinically significant postoperative events after open craniosynostosis surgery. Anesthesiology. 2015; 122:1021-1032.

41. Abuelkasem E, Lu S, Tanaka K, Planinsic R, Sakai T. Comparison between thrombelastography and thromboelastometry in hyperfibrinolysis detection during adult liver transplantation. Br J Anaesth. 2016; 116:507-512. 